\title{
Knowledge, Attitude and Practice Regarding HIV/AIDS among University Students in Xinjiang
}

\author{
Namaitijiang Maimaiti (Corresponding author) \\ United Nations University -International Institute for Global Health \\ Universiti Kebangsaan Malaysia Medical Center \\ Jalan Yaacob Latiff, Bandar Tun Razak, Cheras \\ 56000 Kuala Lumpur, Malaysia \\ Tel: 6-03-9171-5394E-mail: nmu998@yahoo.com \\ Khadijah Shamsuddin \\ Department of Community Health, Faculty of Medicine \\ Universiti Kebangsaan Malaysia \\ Jalan Yaacob Latiff, Bandar Tun Razak, Cheras \\ 56000 Kuala Lumpur, Malaysia \\ Anwar Abdurahim \& Nurungul Tohti \\ Xinjiang University \\ No 14, Ghalibiyat Road, 830048 Urumqi City, Xinjiang, China \\ Rena Maimaiti \\ Xinjiang Medical University \\ No8 Xinyi Road, Urumqi City 830054 Xinjiang, China
}

\begin{abstract}
Objective: The aim of this paper is to assess the level of knowledge on HIV/AIDS and its risk factors, attitude towards HIV/AIDS and AIDS patients and its transmission, and to identify high risk behaviors associated with HIV/AIDS among university students in the Xinjiang Uyghur Autonomous Region. Methodology: A crosssectional survey was conducted among students enrolled in two universities, the Xinjiang University (XU) and Xinjiang Medical University (XMU). Data was collected using validated self-administered standardized questionnaire on knowledge, attitude and practice regarding HIV/AIDS among 200 students from XU and 200 students from XMU who agreed to participate in the study Result: Among the 400 students who participated in the study, the mean knowledge score was $19.3 \pm 5.5$ and their knowledge score ranged from 2 to 30 . Two hundred and ninety eight (74.5\%) students had knowledge score above 15 . Mean knowledge scores were significantly higher among males $(p=0.04)$, those who majored in medical courses $(p=0.01)$, those in the final year of study in university $(p=0.04)$ and by ethnicity, among Han Chinese $(p=0.00)$. However only 33.3\% of the students had positive attitude towards HIV/AIDS and patients with HIV/AIDS. Mean attitude scores were not significantly different by sex, study major, year of study or ethnicity. With regards to high risk behaviors associated with HIV transmission, $15.8 \%$ of these students had at least one risk behavior related to unprotected sexual exposure. High-risk behavior was significantly higher among males $(\mathrm{p}=0.03)$ and first year students $(\mathrm{p}=0.03)$. Conclusion: Our study found most Xinjiang university students had good knowledge, but negative attitude towards HIV/AIDS and HIV/AIDS patients, and $15 \%$ of them reported having at least one high-risk behavior related to sex and unprotected sex. Thus HIV/AIDS health education efforts should be intensified to change attitude and practice among university students in Xinjiang especially among female students, newly enrolled students, and among the Uyghur and other minority students.
\end{abstract}


Keywords: KAP, HIV/AIDS, Sexual health, Risk behaviors, Medical and non-Medical students, Xinjiang China

\section{Introduction}

Acquired Immunodeficiency Syndrome (AIDS) has become one of the most serious health problems in the world. Since China's first detected case of HIV in 1985, the official estimate of HIV cases in the country had reached 650,000 at the end of 2005, yielding a national infection rate of 0.05 percent (Ministry of Health China, UNAIDS and WHO 2005). About three-quarters of these infected people live in five Chinese provinces: Yunnan, Henan, Xinjiang, Guangxi and Guangdong. Today, people living with HIV/AIDS are present in all the 31 provinces and municipalities of China. Although the 2005 estimate of 650,000 cases is lower than the previous figures, the epidemic is spreading more rapidly, with an estimated 70,000 new cases of HIV infection and 25,000 AIDS deaths per year as of 2005 (Ibid). However, these figures are only estimates. About half a million or more persons in China, or about 80 percent of those HIV-positive, do not know their status and the health authorities do not know who they are (National Population and Family Planning Commission of China 2006). A survey recently conducted among some 1,000 people in four Chinese municipalities suggests that 72.6 percent of respondents think HIV/AIDS has nothing to do with them, and that they cannot personally take steps to contain the epidemic (National Population and Family Planning Commission of China 2006). Furthermore, there is widespread agreement that HIV transmission is moving from within the so-called "high risk groups" into the general population, mostly through unprotected sexual relations. Public awareness about the epidemic continues to be fairly low, increasing the opportunity for the epidemic to spread rapidly. In 2003, the United Nations Joint Program on HIV/AIDS (UNAIDS) projected that the number of people living with HIV/AIDS in China will exceed 10 million by 2010 if the country does not mount a prompt and aggressive response (UNAIDS 2004).

As for Xinjiang Uyghur Autonomous Region of China, the first HIV positive case was discovered in 1995, although it is likely the disease was present there many years prior to this time (People's Daily 2004). Since then the number of HIV cases in Xinjiang has risen considerably. As of June 30, 2006, the number of confirmed HIV/AIDS cases in Xinjiang had reached 16,035. However according to the official estimates, there are some 60,000 HIV-positive persons living in Xinjiang, making it the fourth most-affected province in terms of total cases (Gill \& Song 2006). Demographically, Xinjiang is also more populated by minorities especially Muslim Uyghur compared other areas which are dominated by Han Chinese. HIV is efficiently spread through the sharing of needles by intravenous drug users (IDUs). Until recently, IDUs made up the vast majority of HIV cases in China, and this was particularly the case in Xinjiang. Xinjiang borders eight other countries including Afghanistan, Pakistan and the newly independent Central Asian countries some of which are well known poppy growing areas and sources of drugs. In the past, over two-thirds of Chinese HIV infections were contracted through intravenous drug use with infected needles. Although the nationwide proportion of new HIV positive cases contracted through intravenous drug use declined to 48.6 percent in 2005, the spread of HIV through intravenous drug use will remain significant and difficult to combat. Official data published in 2005 show that HIV prevalence among IDUs has more than tripled from 1.95 percent in 1998 to 6.48 percent nationwide in 2004 (Gill \& Song 2006). In some areas of Xinjiang, the HIV prevalence rate among IDUs has reached a staggering 89 percent (MOH of China, UNAIDS and WHO 2005).

Globally, it is known that there is a lack of HIV knowledge among youth between the ages of 15-24. The World Health Organization states that youths are at the epicenter for preventing the progression of the HIV/AIDS pandemic (WHO, 2004). The WHO estimates that youths ages 15 to 24 comprise 50\% of all new HIV infections and consequently must be targeted for education in decreasing transmission and reducing the stigmatization of an HIV diagnosis (WHO, 2004).

In many parts of the world, young people in this age-group are at particularly high risk of HIV infection from unprotected sex, sex between men and IV drug-use because of the very high prevalence rates often found amongst people who engage in these behaviors. Young people are also often especially vulnerable to exploitation that may increase their susceptibility to infection. For Xinjiang, there has been a series of studies conducted in various parts of the region on various topics in health but there are few published studies on HIV/AIDS among medical students non of studies have been geared towards HIV/AIDS among university students. A study on medical students was conducted in 2007 but to date there are no studies comparing university students who enrolled in medical and nonmedical programs as well as by other characteristics of students in Xinjiang. Our study was conducted among medical and non-medical students. It is prudent to conduct this study among university students in Xinjiang in order to ascertain their knowledge, attitude and practice (KAP) regarding HIV/AIDS. University students in general are the most educated of the youths and their KAP on health can be an indicator of the magnitude of the problem among youths in Xinjiang. 


\section{Aims}

The aims of this study were to assess the level of knowledge on HIV/AIDS and its risk factors, attitude towards HIV/AIDS and AIDS patients and its transmission, and to identify high risk behaviors associated with HIV/AIDS among university students in Xinjiang.

\section{Methodology}

\subsection{Study Design and Data Collection}

A cross-sectional survey was conducted using self-administered questionnaires among university students in two public universities in Urumqi Xinjiang. These were students who registered for non-medical degree programme in Xinjiang University (XU) and the medical degree programme in Xinjiang Medical University (XMU). Students were informed of the study prior to their class sessions and were encouraged to participate. Those who agreed to participate were asked to complete a set of questionnaires. The questionnaires were distributed to the students at the end of their scheduled class sessions with cooperation of the lecturer in charge. The questionnaires were completed in class and took an average of twenty minutes to complete. The completed questionnaires were retrieved immediately after the sessions.

\subsection{Sample size and sample selection}

The sample size of the study should be between 392 and 524 respondents. These figures were obtained after considering sample size calculation based on a two-sided hypothesis tests for two population proportions (Lwanga and Lemeshow, 1991). Assuming level of significance at 5\%, power of 80\%, smallest prevalence of P1 or P2 (e.g. proportion of practice level in two populations/groups) at $45 \%$, and the difference in two populations (P1-P2) at 0.1 , the sample size will be 392. However, if power is $90 \%$ and all other parameters being equal, the sample size should be 524. However because of time and cost constraint we decided to collect data from a sample of 400 students.

Samples were purposively selected to include equal numbers of students by sex, year of enrolment and study major (medical or non-medical). In this study we collected data from 100 first year non-medical students and 100 final year non-medical students from XU, while the other respondents were 100 first year medical students and 100 final year medical students from XMU. We also selected 200 male and 200 female students distributed by year of enrollment from the 2 universities. For XU, we selected students from Law programme and IT programme. For $\mathrm{XMU}$, we only selected students from the medical Programme.

\subsection{Study location}

This study was conducted in Xinjiang Uyghur Autonomous Region of the People's Republic of China. Xinjiang is in the North-Western part of China and is a large, sparsely populated area (spanning over 1.6 million sq. km) which takes up about one-sixth of the country's territory. Xinjiang borders the Tibet Autonomous Region to the south and Qinghai and Gansu provinces to the southeast, Mongolia to the east, Russia to the north, and Kazakhstan, Kyrgyzstan, Tajikistan, Afghanistan, Pakistan and India to the west. There are about eight public universities and five public colleges in Xinjiang but this study was carried out in Xinjiang University and Xinjiang Medical University, two of the six public universities located in the city of Urumqi, the capital of Xinjiang. The total enrolment of XU was 38,000 students while that of XMU was around 12,400 students.

\subsection{Questionnaire}

The study instrument was a self-administered questionnaire which comprised of four parts. Part A related to respondent's socio-demographic background, part B on knowledge regarding HIV/AIDS, Part C on AIDS Attitude Scale, and Part D on high risk behavior or practice related to HIV/AIDS transmission.

The knowledge, attitude and practice questionnaire was modified from the instrument used by a survey on HIV/AIDS knowledge, attitude \& practice (KAP) reported by the Department of Education, Free State South Africa (2006) which was adopted from the WHO AIDS Questionnaire (WHO 1990). Knowledge was assessed using a 31item questionnaire which includes knowledge on ways of infection, myths, disease detection and progression, and treatment and prevention of HIV/AIDS. Attitude was assessed using a 10-item questionnaire on attitude towards HIV/AIDS and with HIV/AIDS patients. The questions on high risk behaviors had 11 items related to unprotected sex and needle sharing. The English questionnaire was translated into simple Chinese and back translated into English. Prior to the survey, the questionnaire was pre-tested to assess its clarity, sequencing and time needed to complete. Pre- test of questionnaire was done on twenty respondents who were chosen to ensure that the questions are easily understood. The result of the pre-test was used to improve the phrasing of questions in the questionnaire. 
Questionnaire validation tests showed that the Alpha Cronbach was 0.87 for knowledge, 0.71 for attitude and 0.72 for risk behaviors.

\subsection{Scoring}

For knowledge, each right response was given a score of 1 while a wrong or unsure response was scored 0 . Total knowledge scores can range between 0-31. Knowledge scores from 0 to 15 were considered as poor knowledge while knowledge scores more than 15 was considered as having good knowledge regarding HIV/AIDS. Attitude towards HIV/AIDS patients was assessed using a 10-item questionnaire where attitude scores between 0 to 5 were considered as negative attitude, and scores 6 to 10 were considered as positive attitude. High risk behavior or practice was assessed using an 11-item questionnaire where report of at least one negative behavior related to HIV transmission is considered as having high risk behavior.

\subsection{Ethics consideration}

The study proposal was approved by the Universiti Kebangsaan Malaysia Medical Research and Ethics Committee, (Ethics Approval Reference FF-173-2008). Prior to data collection, all study participants were given information on the study and assured that all data is confidential and will only be analyzed as aggregates. All respondents signed the informed consent form before participation.

\section{Result and Discussion}

Data analysis was done using Statistical Package for Social Sciences (SPSS) Version 12. We described sociodemographic distribution using frequency and percentage and for analysis of the risk factors of KAP, we used the Chi-square test.

\subsection{Response Rate}

Four hundred students agreed to participate and completed the questionnaire after open recruitment of students in the selected faculties at the two universities. Thus we achieved 100 percent of the sample size we set for our study.

\subsection{Student's profile}

The mean age of the 400 respondents was $21.5 \pm 4.0$ years, and ranged from 18 to 25 years. There were 29 (7.3\%) 18 year-, 59 (14.5\%) 19 year-, 81 (20.3\%) 20 year-, 117 (29\%) 23 year-, 79 (19.8\%) 24 year-, and 35 (8.8\%) 25 yearold respondents. In the study the majority of them, 381 (95.3\%) were single, 10 (2.5\%) were married and $9(2.3 \%)$ were divorced. With regards ethnicity, 190 (47\%) of the respondents were Uyghur, 154 (38.5 \%) were Han Chinese and 56 (14\%) were other minorities. By design we had 200 male and 200 female respondents.

\subsection{Outcome of study}

\section{HIV/AIDS knowledge}

Among the 400 respondents, only 109 (27.3\%) respondents had attended an HIV/AIDS related lecture or training programme in their university. Table 1 shows the level of knowledge for all respondents and comparison by sex, study major, year of study and ethnicity. Most of the students, (74.5\%) had good level of knowledge with total scores of more than 15 . More than $80 \%$ of the respondents knew that HIV/AIDS could be transmitted via sharing syringes/needles as well as vertical transmission from mother to child, and about $65-75 \%$ thought condom can prevent HIV transmission during sexual intercourse. However many misconceptions still remain, for instance, 43.2\% of them did not know it is possible to have a negative HIV blood test in the first couple of months after becoming infected with HIV; 59.5\% thought one can get HIV through mosquito bite; and 38.5\% thought HIV/AIDS is homosexual (gay) people's disease. Overall mean knowledge score for the 400 respondents was 19.3 \pm 5.5. Their knowledge scores range from 2 to 30. Mean knowledge scores was significantly different by sex ( $\mathrm{p}=0.04$ ), study major ( $\mathrm{p}=0.01)$, year of study $(\mathrm{p}=0.04)$ and ethnicity $(\mathrm{p}=0.00)$ in university.

$<$ Table $1>$

\section{Attitudes towards HIV/AIDS}

Generally only 33.8\% of respondents had positive attitude towards HIV/AIDS and patients with HIV/AIDS. Our analysis showed $86.0 \%$ of the respondents indicated that people with HIV\&AIDS are like any of them and need their help and support. However our analysis also showed $84.3 \%$ of the respondents thought their friends will avoid them if they were found to be HIV positive; 75.8\% felt it will not be easy for them to tell their friends they are HIV positive; $70.3 \%$ thought they will be dismissed from the university if they were found to be HIV positive; $54.0 \%$ felt 
that persons with HIV/AIDS deserve it; 52.5\% reported they will not be comfortable to study with students who are HIV positive; $51.5 \%$ felt that students infected with HIV/AIDS should have separate washing and toilet facilities at school and 30.0\% felt that HIV infected students should be treated differently. The attitude scores can range between 0-10 and the mean attitude scores was $4.82 \pm 1.85$. Mean attitude scores were not significantly different by sex, year of study, study majored or ethnicity.

$<$ Table 2>

\section{Risk behaviors}

Table 3 shows $15.8 \%$ of all respondents had at least 1 risk behavior related to HIV/AIDS transmission. About $10 \%$ reported having unprotected sex (sex without condom); 6.0\% had more than 1 sexual partner; 3.3\% reported having sex with sex workers; and $4.5 \%$ reported having sex under the influence of alcohol. In this study, $19.5 \%$ Uyghur, $11.0 \%$ Han Chinese, and $16.1 \%$ other minorities reported a least 1 high risk behavior but the difference by ethnicity was not statistically significant $(\mathrm{p}=0.095)$. However, significant more male than female students reported having risk behavior $(\mathrm{p}=0.039)$. We found no significant behavior difference between medical and non-medical students $(\mathrm{p}=0.680)$ and contrary to our beliefs, more first year students reported risk behaviors compared to their final year seniors $(\mathrm{p}=0.039)$.

$<$ Table 3>

\subsection{Discussion}

This study showed that in general students in Xinjiang had relatively high level of knowledge on issues related to HIV/AIDS transmission, since $74.5 \%$ of the respondents had good level of knowledge. This study also found that more medical students had good knowledge than non-medical students but their attitude towards HIV/AIDS and patients with HIV/AIDS was not significantly different. Knowledge of the first year students was also lower than their seniors. This was similar to a study conducted by Nei and Shen (2006) on the knowledge, attitude and behavior status on AIDS among college students in Guangzhou. Nei and Shen (2006) found the level of knowledge was significantly different between medical students and non-medical students and year of study in university. Lönn, et.al (2007) conducted a study among medical students in the Xinjiang Medical University in 2006 and found that all but one student had heard about HIV/AIDS and approximately 95\% knew the most common routes of transmission are sexual contact, mother-to-child transmission, and sharing needles. Eighty percent also knew that HIV in breast milk can be transmitted through breastfeeding. However, based on in-depth interviews of 20 students who participated in his study, Lönn et.al found the students' knowledge of HIV/AIDS seems superficial. A study by Xiaodong Tan (2006) on HIV/AIDS knowledge, attitudes and behaviors among undergraduate students in China, found that students majoring in medicine performed better (more knowledgeable and tolerant) than non-medical students.

Only a third (33.8\%) of the students in this study had positive attitude towards HIV/AIDS and patients with HIV/AIDS. This finding was lower than that found in a study by Zou and Wang (2006) based on a survey of AIDS knowledge, attitude and behavior among students in Linyi City. In that study they found that $41.5 \%$ of students had positive attitude towards HIV/AIDS patients. In this study we found $24.3 \%$ respondents indicated that it would be easy for them to tell their classmates that they are HIV positive. This is similar to Lönn, et.al study on medical students in northwestern China, who found $28 \%$ of the undergraduate and $17 \%$ of the postgraduate students would not tell anyone if they were infected with HIV. Many studies have reported good knowledge on HIV/AIDS but negative attitude is still prevalent. From our study, although students had good knowledge regarding HIV/AIDS, they still harbor negative attitude towards HIV/AIDS and HIV/AIDS patients. Knowledge alone is not enough to change attitudes towards people having HIV/AIDS, but deep seated social and cultural factors such as religion, attitude towards ill-health and risk behaviors especially sexual behaviors can affect attitude too.

In this study, $15.8 \%$ of our respondents reported having at least one risk behavior related to unprotected sexual exposure and 3.0\% reported sharing needles. This was higher than the assessment of HIV/AIDS knowledge, attitudes and behaviors of Chinese students made by Tan et al. (2007). Tan et al. found only 6.9\% of students they assessed reported a bad practice. Huang, et.al (2005) study on knowledge, attitude, behaviors, and perceptions of risk related to HIV/AIDS among Chinese university students in Hunan found that $14 \%$ of Chinese university students were sexually active and risk behaviors tended to increase with age. In addition, $24 \%$ of the students in their study considered themselves to be at moderate to very high risk of contracting HIV and $40 \%$ of the sexually active students never used condoms. In this study, almost all our respondents believed condom can prevent HIV but $15.8 \%$ 
of our respondents admitted having at least one risk behavior related to unprotected sexual exposure. In practice, sexually active students are still shy to buy condom, especially among Uyghurs because of religious and sociocultural norms related to youths especially unmarried youths.

This study suggests that the education system needs to implement specific and focused educational programs for students in university and promote health promotion. It is important that university students understand HIV prevention and transmission, as well as develop positive attitude and good practice. The university is a good place and time to have peer education programmes that address self esteem, healthy sexual attitudes, as well as to be socially active, accepting and caring. Taking into consideration the fact that not all students are sexually active, developing messages geared towards them while offering strategies that help students delay sex, refuse sex, or negotiate safer sexual practices should be included. This program must give students an understanding of why it is more advantageous to abstain from sex, without promoting unnecessary fear.

\subsection{Strengths and limitations of the study}

This study examines knowledge, attitude and behaviors on HIV/AIDS among medical and non-medical students from different universities in Xinjiang (Xinjiang University and Xinjiang Medical University). An earlier study in 2007 was only conducted among medical students from the Xinjiang Medical University (Lönn, et.al 2007). Xinjiang as a region is in many ways different from the rest of China due to its long borders and ethnic composition. This study addressed an important issue in this region since Xinjiang borders many countries, some of which are well known poppy growing areas and narcotic trading routes.

There are some limitations in this study. First, this study was designed a cross-sectional survey using selfadministered questionnaires. Information bias may occur since the questionnaires may generate biased and preconceived answers. The questionnaires did not cover contents related to students' religion, family background, income and resident, when in fact, these factors might directly influence their knowledge, attitude and practice regarding HIV/AIDS. Second. The results obtained in this study should not be generalized to all Xinjiang youths or to all university students in Xinjiang since this study was carried out in only two universities in the capital, Urumqi and among students from limited faculties in these two universities.

\section{Conclusion}

Knowledge of HIV/AIDS is good but about two-thirds of the university students in Xinjiang had negative attitude towards HIV/AIDS and HIV/AIDS patients. This negative attitude will lead to discrimination and delay in seeking treatment for fear of discrimination. At the same time about $15 \%$ of these students reported having at least 1 high risk behavior related to sex and unprotected sex. In view of the limited extent of HIV/AIDS awareness programme at the universities, since only $27.3 \%$ of respondents had attended such education programme, the universities should increase their HIV/AIDS health education efforts to all students, and especially to female and non-medical students. It should also target Uyghur and the other minorities since their level of knowledge on HIV/AIDS is significantly lower than that of the Han Chinese. Knowledge alone is not enough to prevent HIV/AIDS but strategies to instill positive attitude and good practice for preventing HIV/AIDS transmission should be implemented.

\section{Recommendations}

The information on the KAP of university students in Xinjiang can reflect the gaps in HIV/AIDS KAP among youths in urban Xinjiang. It is possible that youths not enrolled in institutes of higher learning may be experiencing even greater gaps on knowledge of prevention of HIV/AIDS. Universities in Xinjiang should offer health education programme related to HIV/AIDS prevention among their students. This can help to improve the student's knowledge and correct any misconception regarding HIV/AIDS. High knowledge level improves student's attitude towards HIV/AIDS and training programmes or lectures regarding HIV/AIDS can help students practice good HIV/AIDS prevention behaviors. Beside health education, intervention strategies must focus on behavioral changes towards safer sex, and changing the negative attitude towards HIV/AIDS and those infected with HIV. This is to ensure prevention of rapid transmission of HIV and early screening of exposed youths.

\section{Acknowledgement}

We would like to thank Universiti Kebangsaan Malaysia for funding the study through the University Fundamental Research Grant No. FF-173-2008. We also like to thank all the students who participated in the study, Mr Yasin 
Memet for helping with the data collection, Mr. Ablat Memet, a teacher in No.1 High School, Bagang for entering the data, and to all other individuals who provided support and assistance in the study

\section{Reference}

Gill B., \& Song G. (2006). HIV/AIDS in Xinjiang: A Growing Regional Challenge. Silk Road Studies Program., China and Eurasia Forum Quarterly, 4 (3): 35-50

Huang J, Bova C, Fennie KP, Rogers A, Williams AB. (2005). Knowledge, attitudes, behaviors, and perceptions of risk related to HIV/AIDS among Chinese university students in Hunan, China. AIDS Patient Care STDS, 2005, 19(11):769-77

Lönn E, Sahlholm K, Maimaiti R, Abdukarim K, Andersson R. (2007). A traditional society in change encounters HIV/AIDS: knowledge, attitudes, and risk behavior among students in northwestern China. AIDS Patient Care STDS, 21(1):48-56.

Lwanga, SK, \& Lemeshow, S. (1991). Sample size determination in health studies: A Practical manual. World Health Organization Geneva. p. 38, 39

National Population and Family Planning Commission of Chine, A Survey Report, July 28 2006, <www.chinapop.gov.cn/rkxx/rkxw/t20060728_145024815.html> (August 20 2006).

Nei S. P and Shen B. (2006). Status of knowledge, attitude and behavior about AIDS among college students in Guangzhou. Chinese School Health Journal, 2006 Vol 27 No.

People’s Daily UPDATED: 10:48, http://english.peopledaily.com.cn/200411/14/eng20041114_163837.html November 14, 2004.

People's Republic of China Ministry of Health, Joint United Nations Program on HIV/AIDS (UNAIDS) and World Health Organization. (2006). 2005 Update on the HIV/AIDS Epidemic and Response in China

People's Republic of China Ministry of Health, UNAIDS and WHO (2006). A Joint Assessment Report of HIV/AIDS Prevention, Treatment and Care in China, 11.

Tan, X.D. (2007). HIV/AIDS knowledge, attitudes and behaviors assessment of Chinese students. International Journal of Environmental Research and Public Health, 4(3), 248-253

UNAIDS. (2004). Epidemiological Fact Sheets on HIV/AIDS and Sexually Transmitted Infections, Update China, [Online] Available: http://data.unaids.org/Publications/Fact-Sheets01/china_EN.pdf (August 20 2006); see also "Chinese AIDS Exhibits Attract Attention in Barcelona," <www.china-embassy.org/eng/zt/zgrq/t36656.htm> (August 20 2006).

World Health Organization. (1990). Global Program on AIDS Social and Behavior Research Unit. Research Package: Knowledge, attitude, beliefs and practices on AIDS (KABP). Phase I, Release 20.01.90. Geneva: World Health Organization.

WHO. (2004). On line www.globalhealth.org > key issues > hiv/aids

Xinhua. (November 28 2005). China Has 135,630 Reported Cases of Reported HIV Infection, [Online] Available: http://news.xinhuanet.com/english/2005-11/28/content_3847884.htm.

Xiaodong Tan, Jingju Pan, Dong Zhou, Chaojun Xie, Xinglan Wen, Yan Hong. (2006). HIV/AIDS knowledge, attitudes and behaviors among undergraduate students in China. Journal of US -China Medical Science, ISSN 15486648, USA. Volume 3, No.5 (Serial No.18).

Zoo H.B, Wang J. (2006). Survey of AIDS knowledge, attitude and behavior among normal students in Linyi City. Occupation and Health. ISSN:1004-1257.0.2006-24-062 Volume 24. 
Table 1. Differences in distribution of knowledge level and mean knowledge scores for all respondents and by sex, Year of study, study major and ethnicity

\begin{tabular}{|c|c|c|c|c|c|c|c|c|}
\hline \multirow[t]{4}{*}{ Factors } & & \multicolumn{4}{|c|}{ Knowledge level } & \multirow{4}{*}{ Mean } & \multirow{4}{*}{$S$ td } & \multirow{4}{*}{ p-value } \\
\hline & \multirow{3}{*}{$\mathbf{N}$} & \multicolumn{2}{|c|}{ Good Knowledge } & \multirow{2}{*}{\multicolumn{2}{|c|}{$\begin{array}{c}\text { Poor Knowledge } \\
(0-15)\end{array}$}} & & & \\
\hline & & & & & & & & \\
\hline & & f & $\%$ & f & $\%$ & & & \\
\hline All & 400 & 298 & (74.5) & 102 & (25.5) & 19.3 & \pm 5.5 & \\
\hline Sex & & & & & & & & 0.04 \\
\hline Male & 200 & 158 & $(79.0)$ & 42 & $(21.0)$ & 19.9 & \pm 5.4 & \\
\hline Female & 200 & 140 & $(70.0)$ & 60 & $(30.0)$ & 18.7 & \pm 5.5 & \\
\hline Study major & & & & & & & & 0.01 \\
\hline Medical & 200 & 160 & $(80.0)$ & 40 & $(20.0)$ & 21 & \pm 5.3 & \\
\hline Non-medical & 200 & 138 & $(69.0)$ & 62 & (31.0) & 18 & \pm 5.4 & \\
\hline Year of study & & & & & & & & 0.04 \\
\hline First year & 200 & 141 & $(70.5)$ & 59 & (29.5) & 18.3 & \pm 5.2 & \\
\hline Final year & 200 & 157 & $(78.5)$ & 43 & $(21.5)$ & 20.3 & \pm 5.5 & \\
\hline Ethnicity & & & & & & & & 0.01 \\
\hline Uyghur & 190 & 118 & $(62.1)$ & 72 & (37.9) & 17.6 & \pm 5.7 & \\
\hline Han Chinese & 154 & 114 & $(93.5)$ & 10 & (6.5) & 21.1 & \pm 4.0 & \\
\hline Others & 56 & 36 & $(64.3)$ & 20 & (35.7) & 17.1 & \pm 5.7 & \\
\hline
\end{tabular}

*Based on Chi-square test; significant at the 0.05 level 
Table 2. Differences in distribution of attitude level and mean attitude scores for all respondents and by sex, year of study, study major and ethnicity

\begin{tabular}{|c|c|c|c|c|c|c|c|c|}
\hline \multirow[t]{3}{*}{ Factor } & \multirow[t]{3}{*}{$\mathbf{N}$} & \multicolumn{4}{|c|}{ Attitude } & \multirow[t]{3}{*}{ Mean } & \multirow[t]{3}{*}{ Std } & \multirow[t]{3}{*}{ p-value } \\
\hline & & \multicolumn{2}{|c|}{$\begin{array}{c}\text { Negative scores } \\
(0-5)\end{array}$} & \multicolumn{2}{|c|}{$\begin{array}{c}\text { Positive scores } \\
(>5)\end{array}$} & & & \\
\hline & & f & $\%$ & f & $\%$ & & & \\
\hline All & 400 & 165 & (66.7) & 135 & (33.3) & 4.83 & \pm 1.85 & \\
\hline Sex & & & & & & & & 0.91 \\
\hline Male & 200 & 132 & (66.0) & 68 & (34.0) & 4.76 & \pm 1.99 & \\
\hline Female & 200 & 133 & (66.5) & 67 & (33.5) & 4.89 & \pm 1.69 & \\
\hline Study major & & & & & & & & 0.34 \\
\hline Medical & 200 & 128 & $(64.0)$ & 72 & (36.0) & 4.99 & \pm 1.72 & \\
\hline Non-medical & 200 & 137 & (68.5) & 63 & (31.5) & 4.66 & \pm 1.95 & \\
\hline Year of study & & & & & & & & 0.75 \\
\hline First year & 200 & 134 & (67.0) & 66 & (33.0) & 4.93 & \pm 1.84 & \\
\hline Final year & 200 & 131 & (65.5) & 69 & (34.5) & 4.72 & \pm 1.85 & \\
\hline Ethnicity & & & & & & & & 0.53 \\
\hline Uyghur & 190 & 129 & (67.9) & 61 & (32.1) & 4.64 & \pm 1.87 & \\
\hline Han Chinese & 154 & 97 & (63.0) & 57 & (37.0) & 5.05 & \pm 1.83 & \\
\hline Others & 56 & 39 & (69.6) & 17 & (30.4) & 4.48 & \pm 1.78 & \\
\hline
\end{tabular}

*Based on Chi-square test; significant at the 0.05 level 
Table 3. Distribution of risk behaviors related to HIV/AIDS for all respondents and by sex, study major, year of study and ethnicity

\begin{tabular}{|c|c|c|c|c|c|c|}
\hline \multirow[t]{3}{*}{ Factor } & \multirow[t]{3}{*}{$\mathbf{N}$} & \multicolumn{4}{|c|}{ At least one Risk behavior } & \multirow[t]{3}{*}{ p-value } \\
\hline & & \multicolumn{2}{|c|}{ Yes } & \multicolumn{2}{|c|}{ No } & \\
\hline & & $\mathrm{f}$ & $\%$ & $\mathrm{f}$ & $\%$ & \\
\hline All & 400 & 63 & $(15.8)$ & 337 & $(84.2)$ & \\
\hline \multicolumn{7}{|l|}{ Sex } \\
\hline Male & 200 & 39 & $(19.5)$ & 161 & $(80.5)$ & 0.03 \\
\hline Female & 200 & 24 & $(12.0)$ & 176 & $(88.0)$ & \\
\hline \multicolumn{7}{|l|}{ Study major } \\
\hline Medical & 200 & 30 & $(15.0)$ & 170 & $(85.0)$ & 0.68 \\
\hline Non-medical & 200 & 33 & $(16.5)$ & 167 & $(83.5)$ & \\
\hline \multicolumn{7}{|l|}{ Year of study } \\
\hline First year & 200 & 39 & $(19.5)$ & 161 & $(80.5)$ & 0.03 \\
\hline Final year & 200 & 24 & $(12.0)$ & 176 & $(88.0)$ & \\
\hline \multicolumn{7}{|l|}{ Ethnicity } \\
\hline Uyghur & 190 & 37 & $(19.5)$ & 153 & $(80.5)$ & 0.09 \\
\hline Han Chinese & 154 & 17 & $(11.0)$ & 137 & $(89.0)$ & \\
\hline Others & 56 & 9 & (16.1) & 47 & (83.9) & \\
\hline
\end{tabular}

*Based on Chi-square test; significant at the 0.05 level 